\section{Newsletter of the}

International Energy

Agency Solar Heating

and Cooling Programme

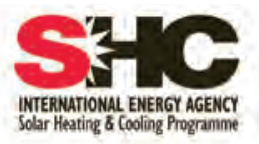

\section{In This Issue}

Solar Resources Knowledge Management

SHC 2013 Conference \section{I}

New SHC Publications

Polymeric Solar Thermal

System Concepts

MarketPlace

Compact Thermal Energy Storage

Singapore

Lighting Retrofit

\section{Managing our Knowledge of the Earth's Solar Resources}

The use of satellite imagery, in conjunction with quality ground data sets and other meteorological information, has become an increasingly important and effective way of developing solar resource assessments over large areas. Satellites can take images of large areas of the earth's surface, and this imagery can then used to produce estimates of solar resources at the earth's surface at high spatial and temporal resolutions. The costs of this approach are considerably lower than if the same information were developed using a ground-based network, although generally the satellite-derived solar resources have lower accuracy than ground-based instruments.

A number of organizations around the world have developed various approaches for producing these assessments, but it was not until the work of SHC Task 36: Solar Resource Knowledge Management that the individual methods were cross-compared and benchmarked with each other. In addition, Task 36 has created efficient ways to access these data sets via the World Wide Web and has studied solar resource forecasting methods, which are used to support large-scale penetrations of solar technologies into transmission and distribution grids.

The three main objectives of SHC Task 36 were to:

- Provide further standardization and benchmarking of international solar resource data sets to insure worldwide intercomparability and acceptance,

- Provide improved data reliability, availability and accessibility in formats that address specific user needs, and

- Develop methods that improve the quality and the spatial and temporal coverage of solar resource products, including reliable solar radiation forecasts.

\section{KEY FINDINGS}

\section{Comparison of Satellite-Based Solar Data Sets}

One key activity in Task 36 was to develop the procedures for comparing various data sets, both visually and statistically. For example, in Figure I the left side shows a composite of six global horizontal irradiance $(\mathrm{GHI})$ solar resource databases as applied in Europe by the European Commission, Joint Research Centre (Italy). The maps are derived from the gridded values making up each data set; each grid cell varies from about $5 \mathrm{~km}$ to around $100 \mathrm{~km}$ in size, depending on the data set. The right side is a map of the standard deviation of the six values for every grid point. The map shows that the highest variations among the data sets are generally found in regions of complex terrain, such as the Alps, and in more northern latitudes.
SHC Member Countries

Australia

Austria

Belgium

Canada

China

Denmark

ECREEE

European

Commission

Finland

France

Germany

Italy

Mexico

Netherlands

Norway

Portugal

Singapore

South Africa

Spain

Sweden

Switzerland

United States 


\section{Join us at SHC 2013}

\section{September 23-25 in Freiburg, Germany}

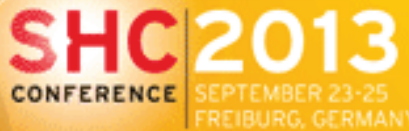

International Conference on Solar Heating and Cooling for Buildings and Industry

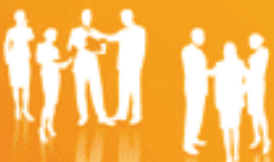

\section{Strong Interest from Industry and R\&D Sector}

The 2nd International Conference on Solar Heating and Cooling for Buildings and Industry, SHC 2013, takes place September 23-25 in Freiburg, Germany. Already interest in the conference is proving to be very strong and the European Copper Institute and solar controller manufacturer RESOL have become Gold and Silver Sponsors. And the number of abstracts submitted has increased by almost I/5th compared to $\mathrm{SHC}$ 2012. Over 295 submissions were received from 49 countries, with Germany leading followed by Italy and Switzerland. And China was the 6th largest contributor of abstracts. As for the abstract topics, "collectors" topped the list followed by "solar-heating and air-conditioning," "other innovative components and systems" and "thermal storage." The conference's scientific committee, headed by Hans-Martin Henning (Fraunhofer Institute for Solar Thermal Energy Systems) and Xavier Noyon (European Solar Thermal Industry Federation), now has the opportunity to select which will be presented orally or as a poster.

\section{Conference dinner in relaxed atmosphere}

Beyond the presentations and papers, SHC will offer a host of interesting side events. For example, the conference dinner will be held in Freiburg's "Market Hall," an authentic location in the city center and very popular with locals and tourists alike. This is a wonderful venue for networking in a relaxed atmosphere while enjoying an international food menu. The evening will end with the presentation of the SHC Solar Award. This year's award will recognize a utility, city, municipality, developer, builder or company with significant achievements in solar thermal market development, in reducing market barriers and/or in the demonstration of large-scale projects.

\section{Technical and sightseeing tours offered}

For those who want to see solar thermal "at work," a number of technical tours are offered. So far four tours under consideration: solar architecture, passive house (multistory building), solar test stands, and Fresnel-collectors and a solar cooling project. Participants also will have the opportunity to visit the Fraunhofer Institute for Solar Energy Systems (ISE). So as not to miss out on tourist opportunities, tours of the old city of Freiburg and the Green City District "Vauban" will be offered.

2012 conference proceedings can be downloaded here.
Up to date information, can be found at www. shc2013.org.
Sponsorship packages are available - please contact info@shc2013.org for more information.
ESTIF is very happy to join the IEA SHC Programme in the organization of SHC 2013. This year's conference has a strong industry focus, and clearly, will be the solar heating and cooling conference of 2013 .

\section{XAVIER NOYON}

ESTIF Secretary General

Conference Dates to Remember

June 18

Notification of

Paper Acceptance

June 18

Online Registration

Begins

September 23-25

Conference Dates 


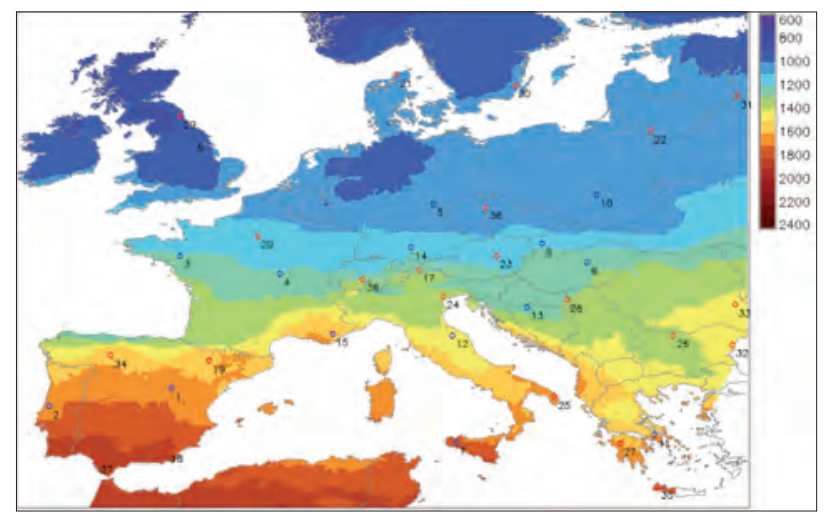

\section{Prototype Web-based Data Portal}

Under Task 36, innovative web tools that allow users to access various data sets for specific purposes or regions have been studied. A common approach for this type of activity is to create a web portal, which steer users to specific data sets that best match requirements queried by the user. A prototype portal was established within the MESoR (Management and Exploitation of Solar Resources project (http://project.mesor.net), a parallel project to Task 36 funded by the EU. The prototype offers access to several sets of data provided by several providers. These data are actually stored at the provider's premises, and can be placed into any format. In this way, the data providers maintain all control over the Web services supplying their data. Figure 2 shows a schematic view of the interface that any user would see in his or her browser based on the scheme developed for Task 36.

\section{Interannual Variability of Solar Resources}

Task 36 undertook several studies to better understand the changes in solar resources that might occur over multiple years. In one study, undertaken by the University of Geneva, ten to fourteen years of ground data acquired at 19 different sites in Europe and the US were used to analyze the solar resource's interannual variability. Measurement-based results were compared to model-derived data sets, such as from satellite observations. An example of these results is shown in Figure 3, which indicates that most of the model-derived data products tested in this study provide yearly values that are within the natural interannual variability range of the observed solar irradiances. When dealing with specific years and time-specific satellite derived data, the interannual variability of the latter follows the ground measurements satisfactorily, especially for the newest algorithms.
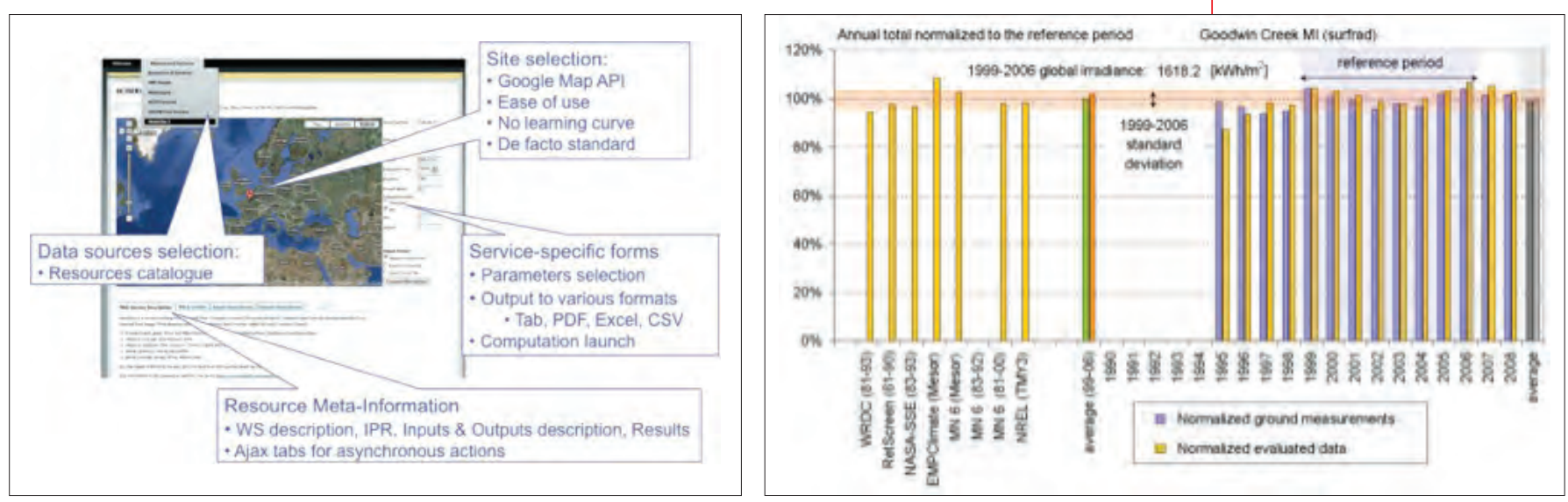

$\triangle$ Figure 2: The prototype of the solar resource information system of SHC Task 36. Source: Armines, France.
- Figure 3: Interannual variability of the normalized annual irradiance for the site of Goodwin Creek (USA). The measurements are represented by blue bars. The green bar represents the 1999-2006 average and the grey bar represents the average over whole period. The derived data are represented by the yellow columns and the average over the reference period in orange. Source: University of Geneva (Pierre Ineichen), Switzerland.
$\Delta$ Figure I: Yearly sum of global irradiation on horizontal surface [kWh/m2]: (left) average of 6 databases: Meteonorm v.6, ESRA, PVGIS, NASA SSE v.6, Satel-Light and HelioClim-; (right) standard deviation of the values from 6 databases relative to the overall average [\%].

Source: Suri et al., EC Joint Research Centre, Italy. 
In another study, Meteotest (Switzerland) examined long-term trends based on data archived in the Global Energy Balance Archive (GEBA). In some cases continuous solar measurements from ground stations are available as far back as the 1940s in the GEBA. An example of the analysis for German stations is shown in Figure 4, indicating periods of global dimming and brightening. The positive trend (brightening) since 1985 is visible until last year and is in the range of $4 \mathrm{~W} / \mathrm{m} 2 /$ decade. However there are signs of a decline of the trend (dimming) after 2005.

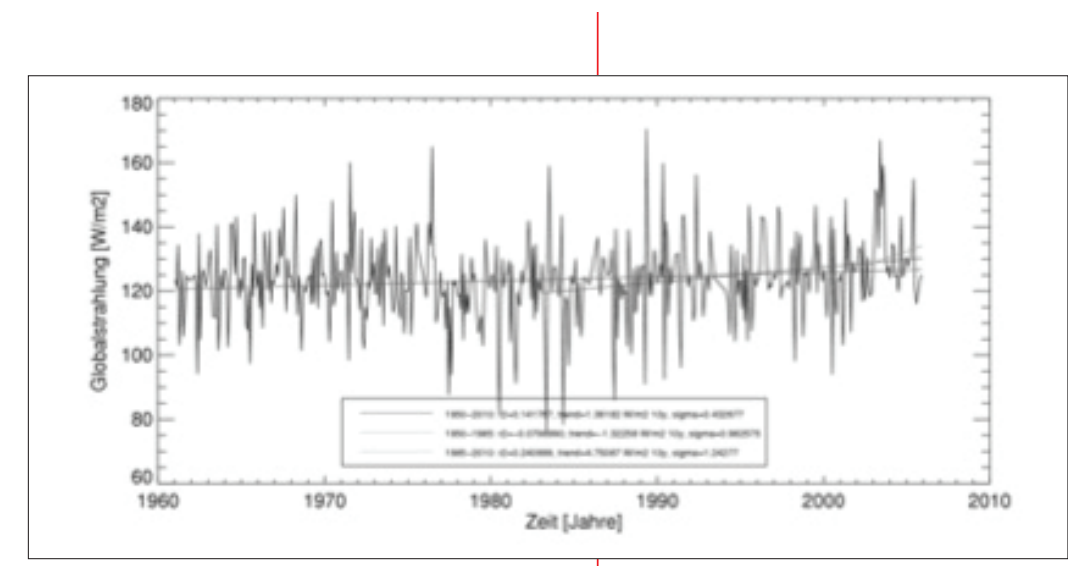

Looking at the moving averages in Figure 4 with smoothing lengths of e.g. 20 years, the changes are generally small. The standard deviation of a 20-year mean in and around Germany is in the range of $1.5-2.0 \%$, which is below the uncertainty of the measurement itself. The $1981-200020$-year mean in Germany is lower by only 2 - $3 \%$ compared to the time period 1986 - 2005. In most other regions the trends are even smaller or, like in China, are even reversed.

These trends are confirmed by satellite-derived data sets developed by NASA/LaRC (U.S.A.), as shown in Figure 5, which present the de-seasonalized monthly anomalies of the downwelling solar irradiance (in W m-2) in the zonal averaging latitude bands of $60^{\circ} \mathrm{N}-60^{\circ} \mathrm{S}$ and $20^{\circ} \mathrm{N}-20^{\circ} \mathrm{S}$ since 1984. The anomaly of the zonally averaged cloud amount is also included in this figure. These data are derived from the NASA/GEWEX Surface Radiation Budget project and ultimately are used to provide solar resource information through the NASA Surface meteorology and Solar Energy web service (SSE). These plots show qualitative agreement with the dimming/brightening short-term changes found in the GEBA archive.

In terms of what these trends might mean for the future, Meteotest (Switzerland) also examined modeled changes in future global radiation for the rest of this century and determined that these are also relatively small and are mostly in the range of a few percent. In contrast to temperature, there are no big changes foreseen in future radiation trends. On a global average the radiation will diminish slightly. In the Mediterranean region however the trend is positive.

\section{Solar Resource Forecasting}

Ten partners of SHC Task 36 worked on the development of different approaches for forecasting solar irradiance from a few hours ahead to several days ahead based on numerical weather prediction NWP models and cloud motion vectors. Several studies coming out of this work were an intercomparison of various solar resource forecasting approaches conducted for the U.S., Canada, and Europe.

Figure 6 shows results of one such study, performed for Spain, Austria, Switzerland and Germany for the period I July 2007 to 30 June 2008. The evaluation revealed a strong dependence of the forecast accuracy on the climatic conditions. For Central European stations the relative Root Mean Square Error (RMSE) ranges from 40\% to 60\%, for the Southern Spanish stations relative RMSE values are in the range of 20\% to $35 \%$. A larger RMSE indicates a higher uncertainty in forecast reliability. Solar irradiance forecasts based on global NWP models in combination with postprocessing showed better results than mesoscale NWP models. All proposed methods perform significantly better than persistence.

$\Delta$ Figure 4: Linear trends are observed throughout the past five decades based on ground measurements obtained from the GEBA for Germany. Source: Meteotest (Jan Remund), Switzerland.

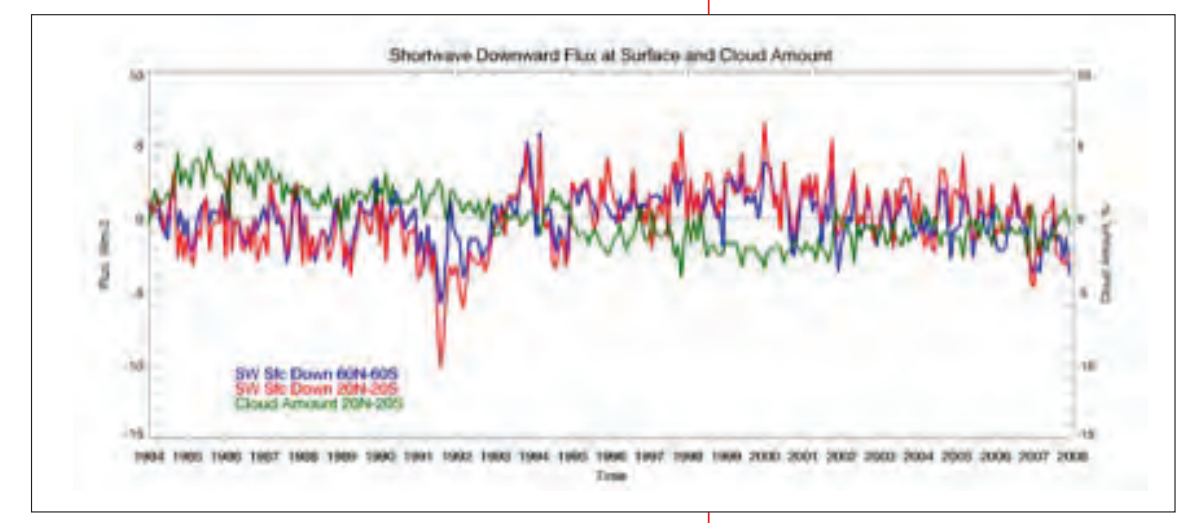
(a) 
Solar Resources Knowledge from page 4

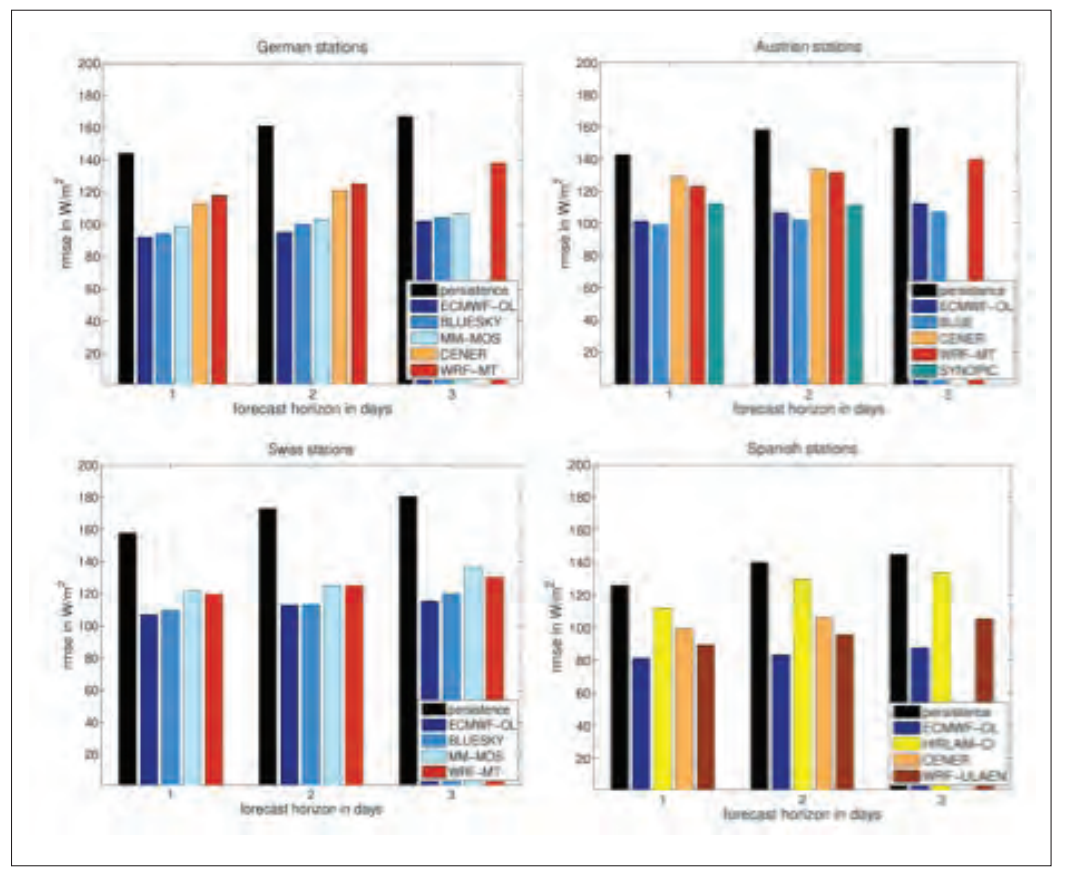

$\triangle$ Figure. 6: Average RMSE for different forecast horizons (one day ahead: 0-24hs, two days ahead: $25-28$ hhours, three days ahead: $29-72 \mathrm{hhours}$ ) for stations from Germany (Imean=227 W/m2), Switzerland (Imean=267W/ $\mathrm{m} 2)$, Austria $(\mathrm{Imean}=222 \mathrm{~W} / \mathrm{m} 2)$, and Spain $(I m e a n=391 \mathrm{~W} / \mathrm{m} 2)$. Higher RMSE's indicate higher uncertainties in forecast skill. Source: University of Oldenburg (Elke Lorenz), Germany.

\section{TRANSITION OF SHC TASK 36 WORK TO TASK 46}

Although the sun has now set on Task 36, which was completed in 2011, it has risen brightly on a new, follow-up project, Task 46: Solar Resource Assessment and Forecasting. Much of the work undertaken in Task 36, including evaluation of solar forecasting schemes, improvements to satellite-derived models, and data qualification and assessment practices to establish data bankability, will be continued or started in Task 46. Furthermore, best practices guidelines for taking ground based solar resource measurements will be developed. Task 46 began in 201I with nearly 75 participants and observers representing 13 countries, expanding into Australia, Denmark, the UK, the United Arab Emirates, and Singapore. Outcomes of Task 46 will be reported in future issues of the Solar Update.

This article was contributed by Dr. David Renné, the Operating Agent for SHC Task 36: Solar Resource Knowledge Management and Task 46: Solar Resource Assessment and Forecasting.

\section{New SHC Publications}

\section{NZEB}

The Net ZEB evaluation tool Net ZEB evaluation tool - is an excel-based tool that enables energy balance, operating cost and load match index calculation for selected definition. It aims at evaluating solutions adopted in new building design with respect to different Net ZEB definitions (for building designers), assessing the balance in monitored buildings (for energy managers), and assisting the upcoming implementation process of Net ZEBs within the national normative framework (for decision makers).

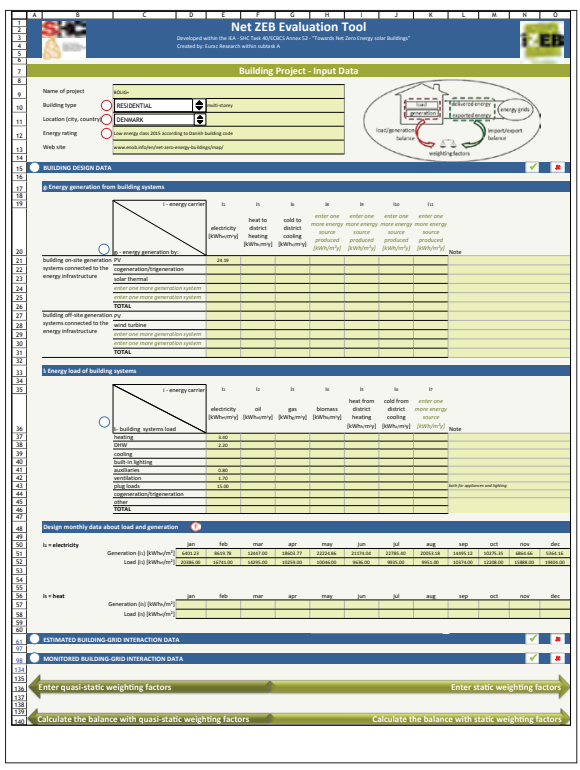

\section{SOLAR RENOVATION IN NON- RESIDENTIAL BUILDINGS}

A set of Exemplary Renovation Projects demonstratingthat total primary energy consumption can be drasticallyreduced while also improving the building's indoor climate is available online. These projects have been systematically analyzed to make them a reliable resource for planners.

Projects will continue to be added to this collection. Recent additions - School in Schwanenstadt, Austria, the Osram Cultural Center in Denmark and the Kampen School in Norway. 


\section{Polymeric Collectors and Components Showcase}

\section{Task 39}

Based on the theoretical groundwork on polymeric collectors and components, SHC Task 39: Polymeric Materials for Solar Thermal Applications has taken the next step towards the implementation of novel polymeric system concepts. At a Task workshop in March, 26 international experts discussed possible system configurations with suitable polymeric components and worked on concrete proposals for their implementation. The results will be showcased at the SHC Conference 2013 in Freiburg, Germany, which plays host to a unique assembly of promising polymeric system concepts.

The SHC Task 39 Exhibition will be the first of its kind to put selected polymeric collectors and components on stage. It will not only highlight the state-of-the-art, but also allow for considerations beyond the latest developments in solar thermal research on polymeric based components and systems.

What is envisioned is the assembly of three system types using commercially available polymeric components - a typical domestic hot water system with forced circulation, a scalable solar thermal system with suitable storage tank, and the exposition of an all-polymeric thermosiphon system. Under the management of Dr. Stephan Fischer (ITW/SWT Stuttgart, leader of Task 39 Subtask B) SHC Task 39 participants are looking for attractive technical examples and financial sponsors to complete the project. Dr. Fischer is extremely happy for the support of Magen Eco-Energy and Aventa AS. These two pioneering companies are sharing their know-how of commercially available all-polymeric collectors, custom-sizable collectors and thermosiphon systems with SHC Task 39. Storage manufacturers and suppliers of piping systems will complete the systems.

Magen and Aventa AS are frontrunners in the production of all plastic solar collectors that are able to withstand demanding climatic conditions, such as high temperatures and UV. Specializing in solar heating for swimming pools and solar water heating systems for domestic and commercial use (e.g., thermosiphon systems) Magen Eco-Energy provides installation solutions around the world. The Norwegian company Aventa AS places a special focus on the aesthetic quality of its products and specifically designs collectors for building integration. The seamless installation of collectors into the building envelope is achieved by modular building elements of different colors as part of roof or façade covers. Both solutions will be shown at SHC 2013.

By highlighting established and novel combinations of polymeric components, the SHC Task 39 Exhibition will

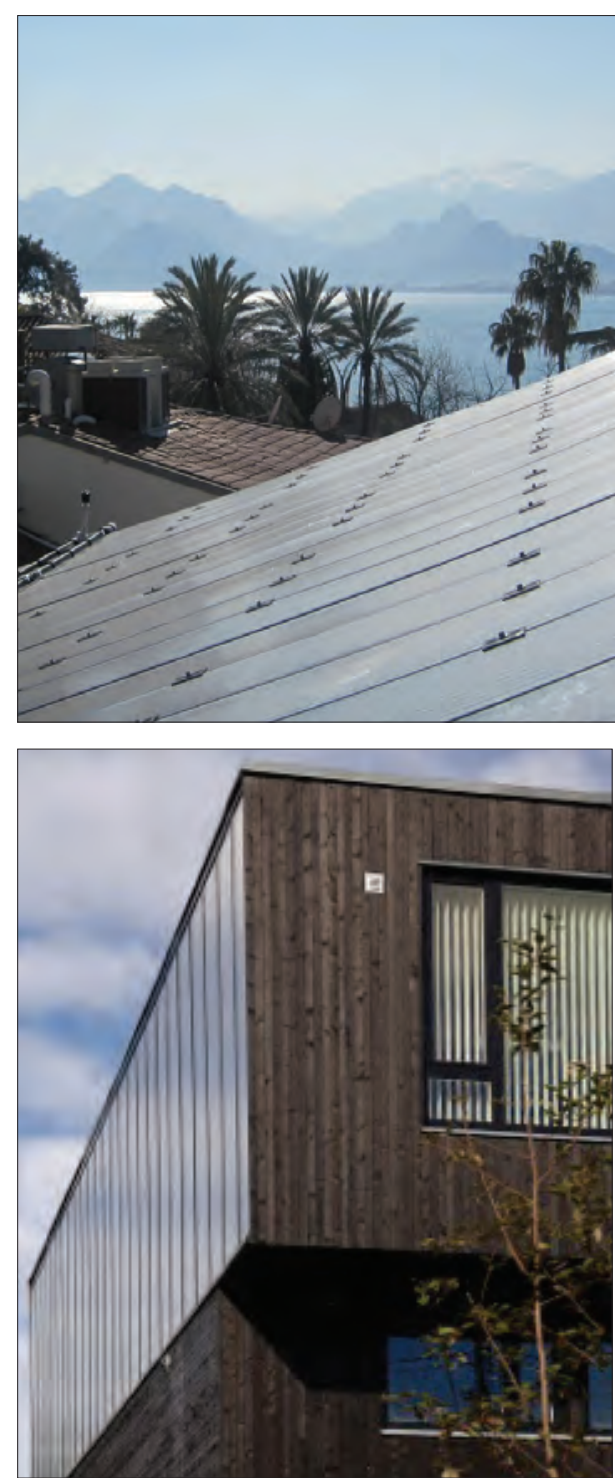

continued on page 6
4 Figure 2. Multi-family house with AventaSolar solar collectors integrated into the façade. Source: Dahle/ Dahle/Breitenstein AS. 
show a range of possibilities for re-thinking solar thermal. "Polymeric materials are the key to costreduction and aesthetical innovations“, states Dr. Michael Köhl, Operating Agent of SHC Task 39 , and explains the motivation behind the planned exhibition, "We have some good products on the market. What needs to be done is to increase peoples' awareness of the great potential we have here, to show that polymers are suitable materials for solar thermal applications and to increase customers' and manufacturers' confidence in these innovative materials, which have already been successfully introduced by aircraft and automotive industries. The exhibition will serve as a platform to demonstrate the feasibility and potential of a new generation of solar thermal technology."

For more information visit the Task 39 website.

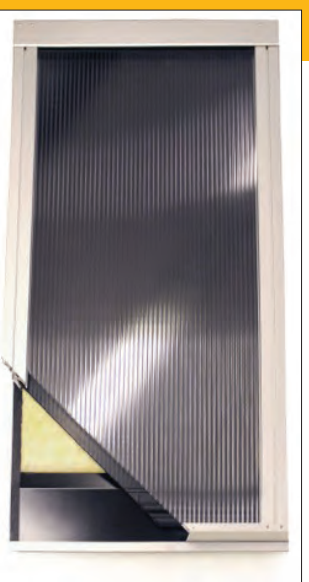

$\triangle$ Figure 3. Setup of an all-polymeric collector. Source: Aventa AS.

\section{MarketPlace}

The Solar Heating and Cooling Programme is not only making strides in R\&D, but also impacting the building sector. This section of the newsletter highlights solar technologies that have been developed or conceptualized in a SHC Task and are now being commercially manufactured, marketed or used.

\section{Ice Storages With Heat Pump Reach Market}

Since 2010 experts in SHC Task 44: Solar and Heat Pump Systems have been investigating combinations of solar and heat pumps for the heat demand of low energy houses. And, several installations have been monitored and the observed data used to further validate simulation models.

One of the monitored installations links a heat pump to an ice storage. This design allows the ice storage to provide a constant temperature source for the heat pump in a somewhat reduced volume, which is possible thanks to the use of one of the best phase change materials (PCM) - water. Freezing water can provide $333 \mathrm{~kJ} / \mathrm{kg}$ of energy at 0 Celsius. Imagine I m3 of storage, that is about $330 \mathrm{MJ}$ or $92 \mathrm{kWh}$ that the heat pump can withdraw. A $6 \mathrm{~kW}$ heat pump with a COP of 3 could operate for about 2 days before the storage is totally iced.

When the sun shines or even when the air temperature allows, the storage can be recharged using unglazed solar collectors. When the ice melts to water the cycle is ready to restart.

Installations of this type have reached seasonal performance factors, as defined by SHC Task 44, of up to 4.5 and improvements can still be seen.

Where boreholes cannot be drilled, when air/water heat pump performance is of concern, or when the airflow would cause a noise problem, the ice storage solution has proved to be a reliable solution.

More and more projects using ice storage are being developed for use in single family homes as well as in medium size buildings where the ice can also be used as a cooling source during the summer.

SHC Task 44 is paving the way for this type of installation to reach standardized performance factors.

For more information go to the SHC Task 44 webpage, or contact SHC Task Operating Agent Jean-

Christophe Hadorn, jchadorn@baseconsultants.com.

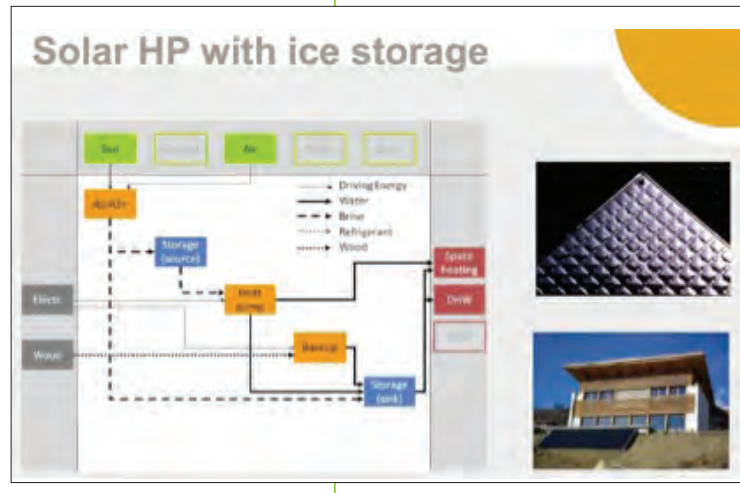

$\Delta$ This house in the Alps is using solar absorbers, a heat pump and an ice storage. 


\section{Advances in Compact Thermal Energy Storage}

\section{Task 42}

The SHC Programme has joined forces with the IEA Energy Conservation through Energy Storage

Programme to develop advanced materials for compact storage systems that are suitable not only for solar thermal systems, but also for other renewable heating and cooling applications such as solar cooling, microcogeneration, biomass, and heat pumps. By combining the knowledge of materials science experts with that of experts in solar/renewable heating and energy conservation experts, great things are happening.

\section{MERITS Developing Thermal Battery Prototypes}

The European Commission has set specific targets to achieve an energy-neutral built environment by 2050 in Europe. With this in mind, Europe is moving closer towards low and zero-carbon buildings and a renewable energy supply, but there are still some big challenges to overcome, including a critical one - energy storage.

Wouldn't it be nice to be able to store the summer heat in a loss-free fashion for use in winter in some sort of "thermal battery"?

The FP7-project MERITS (More Effective use of Renewables Including compact seasonal Thermal energy Storage), coordinated by TNO, The Netherlands, aims to design, build and evaluate prototypes of a compact seasonal solar-thermal energy storage system based on thermochemical storage materials: a thermal battery!

To support this work, the team is actively participating in several of the SHC Task 42: Compact Thermal Energy Storage working groups. Work associated with the MERITS project will focus on novel thermochemical materials with high energy density that can supply the required heating, cooling and domestic hot water for a dwelling with up to $100 \%$ renewable energy sources (sun) throughout the year. The key development issues are I) the delivery of heat at different dedicated temperature levels for heating, cooling and domestic hot water, 2) the tailoring to the requirements of individual dwellings, 3) the design and development of a dedicated solar collector, and 4) the integrated design for the different components and enhanced thermo-chemical materials, including the control system.

In this project, activities in the areas of innovative solar energy collectors, storage materials and components, system integration, and model development will take place, ultimately leading to working prototypes of a full seasonal thermal storage system that will be demonstrated and evaluated in three different climate zones in a field test throughout Europe.

Partners in the project are four research institutes (TNO, VITO, Tecnalia, Fraunhofer), two universities (Ulster University, University of Lleida), two SMEs (De Beijer RTB, Zonne-energie Nederland BV) and three industries (Voestalpine, Mostostal, Seagoe Technologies Ltd.).

$\triangle$ The MERITS principle: solar energy storage for use in heating, cooling and domestic hot water in buildings. 


\section{Advances in Compact Storage from page 8}

This combination of partners maximally guarantees the swift market introduction of a commercial thermal storage system that is ready for application in new homes throughout Europe. The impact of the project is to make the European ambition of realizing an energy-neutral built environment technically feasible!

Article contributed by Christophe Hoegaerts (project leader) and Ruud Cuypers, TNO Energy \& Comfort Systems, Delft, The Netherlands. For more information visit www.merits.eu.

\section{ITW Supporting Advances in Thermochemical Energy Storage}

The Research and Testing Center for Thermal Solar Systems (TZS) at the University of Stuttgart's Institute for Thermodynamics and Thermal Engineering (ITW) is currently conducting research in the field of thermochemical energy storage with a focus on process development and implementation in demonstration plants and on detailed materials investigations.

\section{SolSpaces Project}

This is one of two research projects on thermochemical energy storage for solar thermal systems, operating in an open sorption process. The three-year SolSpaces project started in March 2012 and is building on the results of the MonoSorp project (20052007). The project is tasked with developing a sorption store for energy efficient compact buildings. A pilot system with a sorption store will be tested in a prefabricated compact house of the German company SchwörerHaus KG.

\section{EnErChem Project}

The CWS project, carried out from 2008 to 2012, designed thermochemical energy storage for solar thermal systems as well as for photovoltaic and combined heat and power plants. The results from this project are now being incorporated into the EnErChem project, which is conducting detailed material investigations and demonstrating a thermochemical energy store in a demonstration plant. EnErChem is a joint project between the Institutes for Thermodynamics and Thermal Engineering (ITW), University of Stuttgart, the Institute of Technical Chemistry (ITC), University of Leipzig, the Vaillant Group, and the Chemiewerke Bad Köstritz. This work is supporting the work of SHC Task 42.

In addition to the investigation of long-term heat storage working in open adsorption processes, a thermochemical energy storage working in a closed adsorption process is also being investigated in the EU project COMTES with ITW as one of the partners. The idea for the COMTES project and this new consortium was a result of discussions during SHC Task 42 meetings. Together with AEE-Intec, the University of Wildau, and the Vaillant Group as an industrial partner, an energy store to achieve a high solar fraction (> 50\%) will be developed and tested in a real system-building environment.

Article contributed by Barbara Mette and Henner Kerskes, ITW, Germany. 


\section{Pushing The Frontiers of Green Buildings}

\section{Singapore}

Singapore is a city-state with a land area of about $723.2 \mathrm{~km}^{2}$ and a population of approximately 5.3 million people. Since gaining independence in 1965, the government has always emphasized the importance of sustainability, the integration of the environment with urban development, and the softening of the effects of a concrete jungle. According to the Asian Green City Index , Singapore is Asia's greenest metropolis and has one of the highest concentrations of green buildings in the world in terms of certified green building floor area per capita. This is one example of this green city's holistic approach to city development and environment.

This emphasis on green buildings, in particular on building energy efficiency and environmentally friendly construction processes, encourages industry practitioners to take a holistic project approach by adopting passive and active design principles and incorporating green features and technologies/systems.

\section{Green Buildings through Policy}

Singapore's green building movement started to gain momentum after the launch of the Building and Construction Authority (BCA) Green Mark scheme in 2005. This green building rating system promotes the adoption of green building design and technologies that improve energy efficiency and reduce the impact of buildings on the environment.

The first Green Building Master Plan followed close behind with a launch in 2006. This Plan focused on the greening of new buildings through a package of incentives to encourage developers to strive for excellence in environmental sustainability. In April 2008, the Building Control Act was amended to impose minimum standards on environmental sustainability for new buildings. The minimum statutory requirement was consistent with the standards set out in the Green Mark Certified level. Following this policy intervention, BCA rolled out the 2nd Green Building Master Plan in 2009, which placed greater emphasis on the greening of existing buildings and set a target to green at least $80 \%$ of the buildings in Singapore by 2030.

Currently, there are more than 1,300 buildings that are certified under the Green Mark Scheme, translating to a gross floor area of about 38 million m2, or 17\% of the total gross floor area in Singapore.

The market for new green building projects has been growing robustly as shown in Figure I.

To support this growth, new legislative measures are being taken, which include a mandatory submission of energy consumption and building data and a mandatory audit of building operational system efficiency at every third year of operation. To make buildings more energy efficient, the BCA Green Mark rating criteria were also revised adding new pre-requisites for higher Green Mark awards, such as the need for central chilled water plants to have accurate, permanent measurement and verification instrumentation.

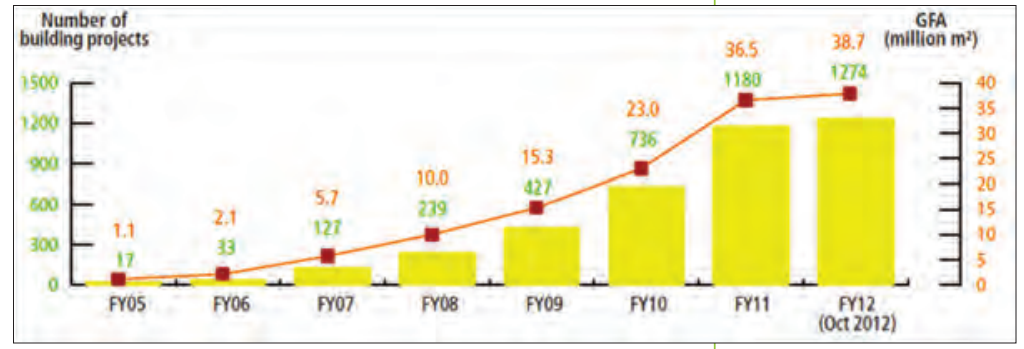

$\Delta$ Figure I.

Singapore's Green Building Figures (cumulative).

To drive the research and development $(R \& D)$ of green building solutions for the tropics, a Green Building
R\&D Framework was developed via a multi-agency effort. The framework serves as a guide for prioritizing near-term R\&D grant calls with the focus of developing high-impact and cost-effective solutions for green buildings. Within the framework (see Figure 2), the technology focus areas, namely: Air-conditioning \& Mechanical Ventilation (ACMV), Highly Efficient Dehumidification, and Innovative Air Distribution \& Cooling are consistent with the Solar Heating and Cooling (SHC) Programme, such as work in SHC Task 48: Quality Assurance and Support Measures for Solar Cooling Systems 


\section{Solar Cooling R\&D Opportunities in the Tropics}

Given its favorable tropical condition, Singapore receives about $50 \%$ more irradiation compared to temperate regions. Due to this higher solar radiation and the effect of the urban heat island from Singapore's densely built environment, space cooling through air conditioners is a necessity. Figure 3 displays the breakdown of energy consumption of proposed buildings based on the Green Mark criteria of nine Platinum and Goldplus buildings. Such negative effects on thermal comfort and the energy consumption of buildings can exacerbate the existing high temperature of the city's urban climate by transpiring a further temperature increase through the environment conducted waste heat (for example the heat rejection of airconditioning).

Taking the above into consideration, the cooling demand will only increase as more buildings are built in the future. Thus, there is great potential to improve the cooling plant system efficiency and push for the adoption of alternative air distribution and cooling technologies, specifically in the area of solar heat for cooling where the sun generates chilled water. The main advantage being that the cooling load and the solar gain occur at the same time.

Despite having no outright energy cost subsidy for solar thermal system deployment in Singapore, growing environmental concerns and emphasis on Green Building R\&D make solar cooling systems R\&D and deployment an important focus area. Currently there are two buildings using solar air-conditioning technology. The United World College of South East Asia (UWCSEA) is fitted with 3,870 $\mathrm{m}^{2}$ of solar panels and has the world's largest solar cooling system. The other solar air-conditioning system is installed at Tampines Grande by City Developments Limited. The solar collectors cover an area of approximately $675 \mathrm{~m} 2$ on the roof. The system is designed to generate enough chilled water to provide cool air to the atrium space.

Solar cooling has the potential of significantly reducing electricity consumption while contributing to energy saving and electrical peak load reduction. As a renewable energy technology, solar air-conditioning is deemed to have a vast marketing potential in the tropical belt. The improved solar cooling systems (e.g., desiccant cooling, sorption systems and solar thermal air conditioning technology) will help address the expected rise in cooling demand in a more energy efficient manner that reduces carbon emission for tropical countries like Singapore.

Article contributed by Zelia Tay and Stephen Mok, Building Construction Authority, Singapore. Singapore is a member of the IEA Solar Heating \& Cooling Programme, for more information contact the Executive Committee member, Mr Ang Kian Seng, ang_kian_seng@bca.gov.sg.

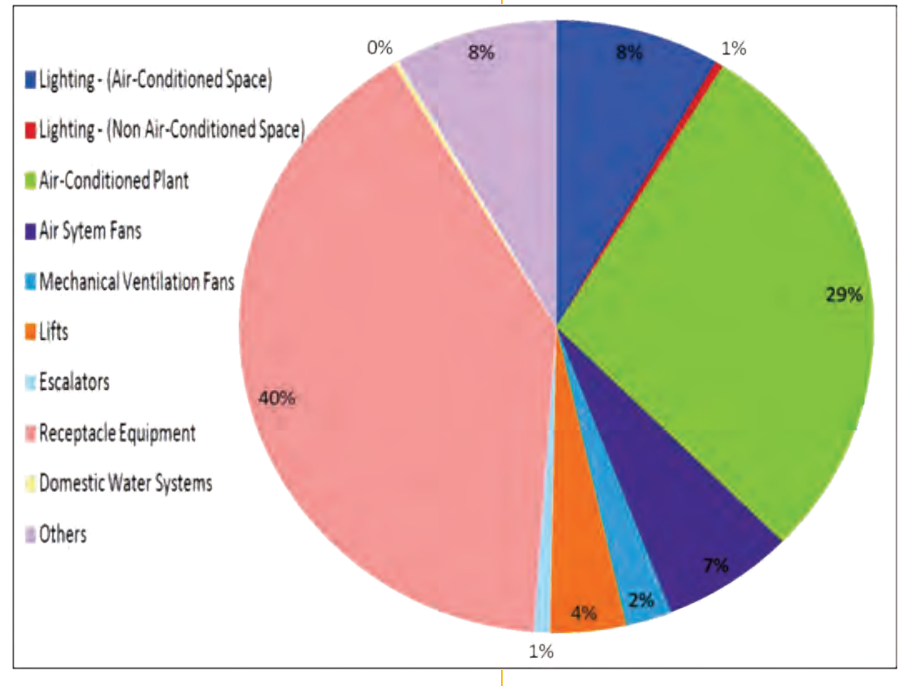

$\triangle$ Figure 2. Green Building Research and Development (R\&D) Framework.

\section{A Figure 3. \\ Distribution of energy consumption of proposed buildings.}




\section{SHC Shines the Spotlight on Lighting Retrofit}

\section{Task 50}

In March 2013, the new Task 50: Advanced Lighting Solutions for Retrofitting Buildings held its Kick-off experts meeting. The meeting opened with an industry workshop at Lund University in Sweden where the fifty attendees discussed and shared insights on a wide range of lighting retrofit issues from improving natural lighting conditions in retrofits to technical and economic issues of solid state lighting (LEDs). It was then time for the Task participants to focus on finalizing the work plan for this 3-year project.

SHC Task 50 is continuing the earlier work of the SHC Programme with a focus this time on accelerating the retrofitting of daylighting and electric lighting solutions in the non-domestic sector using cost effective, best practice approaches that can be applied in a wide range of existing buildings. Over the course of the Task, participants will collaborate to:

- Develop a sound view of the lighting retrofit market.

- Trigger discussion, initiate revision and enhancement of local and national regulations, certifications and loan programs.

- Increase robustness of daylight and electric lighting retrofit approaches technically, ecologically and economically.

- Increase understanding of lighting retrofit processes by providing adequate tools for different stakeholders.

- Demonstrate state-of-the-art lighting retrofits.

The Task will conclude with the publication of an electronic, interactive sourcebook of design inspirations, design advice and decision tools.

To manage the work, SHC Task 50 is subdivided into four Subtasks with a Joint Working Group to connect the activities and combine all the results. The first activity of the participants is gathering information on typical lighting installations in the participating countries to create a solid overview of the building stock; in other words taking stock of what is out there. This work will serve as the basis for several activities benchmarking, identification of market specifics and selection of best-practice case studies.

Patterns and market strategies for approaching lighting retrofit projects have already been identified and discussed. And shortly, a questionnaire will be sent to key actors involved in building retrofit to help identify stakeholder interests. In addition to this baseline work, Task participants are looking deeper into the state-of-the-art technical solutions, methods and tools to help identify a group of case studies that will be assessed during the Task.

For more information visit the Task 50 website or contact the Operating Agent Jan de Boer at task50.info@ iea-shc.org.
IEA SHC-Task 50

Advanced lighting solutions for retrofitting buildings

Operating Agent: I. de Boer, DE

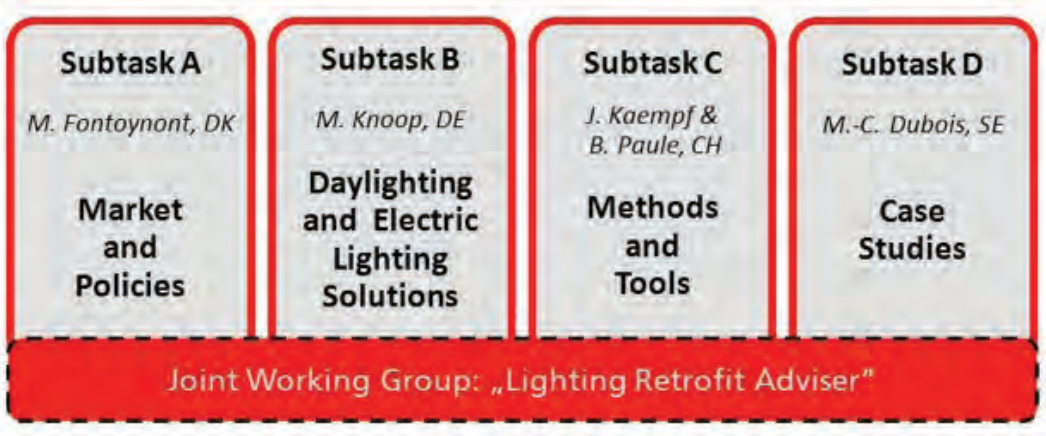

$\triangle$ Structure of

IEA SHC Task

50: Advanced

Lighting Solutions

for Retrofitting

Buildings. 


\section{Current Tasks and Operating Agents}

Polymeric Materials for Solar

Thermal Applications

Dr. Michael Köhl

Fraunhofer Institute for Solar Energy

Sytems

Heidenhofstr. 2

D-79 IIO Freiburg

GERMANY

michael.koehl@ise.fraunhofer.de

ment a program of international energy

cooperation among its member countries,

including collaborative research, develop-

ment and demonstration projects in new

energy technologies. The members of the

IEA Solar Heating and Cooling Agree-

ment have initiated a total of 49 R\&D

projects (known as Tasks) to advance solar

technologies for buildings. The overall

Programme is managed by an Executive

Committee while the individual Tasks are led by Operating Agents.

\section{Follow IEA SHC on}

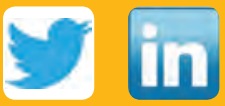

\section{$S \bigcirc L A R U P D A T E$}

The Newsletter of the IEA Solar Heating and Cooling Programme

Vol.58, June 2013

Prepared for the IEA Solar Heating and Cooling Executive Committee

by

KMGroup, USA

Editor:

Pamela Murphy

This newsletter is intended to provide information to its readers on the activities of the IEA Solar Heating and Cooling Programme. Its contents do not necessarily reflect the viewpoints or policies of the International Energy Agency or its member countries, the IEA Solar Heating and Cooling

Programme member countries or the participating researchers.

\section{Toward Net Zero Energy Solar}

\section{Buildings}

Mr. Josef Ayoub

CanmetENERGY

Natural Resources Canada

1615, boul. Lionel-Boulet

Varennes, Quebec J3X IS6

CANADA

Josef.Ayoub@rncan-nrcan.gc.ca

\section{Compact Thermal Energy Storage}

Mr. Wim van Helden

Renewable Heat B.V.

Oosterstraat 15

|74| GH Schagen

NETHERLANDS

wim@wimvanhelden.com

\section{Solar Rating and Certification}

\section{Procedures}

Mr. Les Nelson

IAPMO Solar Heating \& Cooling

Programs

500I E. Philadelphia Street

Ontario, CA 91761

les.nelson@iapmo.org
Mr. Jan Erik Nielsen

SolarKey International

Aggerupvej I

DK-4330 Hvalsö

DENMARK

jen@solarkey.dk

Solar and Heat Pump Systems

Mr. Jean-Christophe Hadorn

BASE Consultants

8 rue du Nant - CP 6268

$\mathrm{CH}$ - 12I| Genève 6

SWITZERLAND

jchadorn@baseconsultants.com

Large Systems: Large Solar

Heating/Cooling Systems,

Seasonal Storage, Heat Pumps

Mr. Jan Erik Nielsen

SolarKey International

Aggerupvej I

DK-4330 Hvalsö

DENMARK

jen@solarkey.dk

Solar Resource Assessment

and Forecasting

Dr. David Renné

2385 Panorama Ave.

Boulder, CO 80304

UNITED STATES

drenne@mac.com

\section{Solar Renovation of Non-}

Residential Buildings

Mr. Fritjof Salvesen

Asplan Viak AS

P.O.Box 24

I300 Sandvika

NORWAY

fritjof.salvesen@asplanviak.no
Quality Assurance and Support

Measures for Solar Cooling

Mr. Daniel Mugnier

TECSOL SA

105 av Alfred Kastler - BP 90434

66004 Perpigan Cedex

FRANCE

daniel.mugnier@tecsol.fr

Solar Process Heat for Production and Advanced Applications

Mr. Christoph Brunner

AEE INTEC

Feldgasse 19

A-8200 Gleisdorf

AUSTRIA

c.brunner@aee.at

\section{Advanced Lighting Solutions for}

Retrofitting Buildings

Dr. Jan de Boer

Fraunhofer Institute of Building Physics

Nobelstr. 12

D-70569 Stuttgart

GERMANY

jdb@ibp.fraunhofer.de

\section{Solar Energy in Urban Planning}

Ms. Maria Wall

Dept. of Architecture and Built Environment Lund University

P.O. Box 118

SE-22I 00 Lund

SWEDEN

maria.wall@ebd.Ith.se

Member Countries and Execulive Commitiee Members

$\begin{array}{llll}\text { AUSTRALIA } & \text { Mr. K. Guthie } & \text { ITALY } & \text { Mr. M. Zinzi } \\ \text { AUSTRIA } & \text { Mr. W. Weiss } & \text { MEXICO } & \text { Dr. W. Rivera } \\ \text { BELGIUM } & \text { Prof. A. De Herde } & \text { NETHERLANDS } & \text { Mr. L. Bosselaar } \\ \text { CANADA } & \text { Mr. D. McClenahan } & \text { NORWAY } & \text { Dr. T. Wigenstad } \\ \text { CHINA } & \text { Prof. H. Tao } & \text { PORTUGAL } & \text { Mr. J. F. Mendes } \\ \text { DENMARK } & \text { Mr. J. Windeleff } & \text { SPAIN } & \text { Dr. M. Jiménez } \\ \text { ECREEE } & \text { Mr. J. Delgado } & \text { SINGAPORE } & \text { Mr. K. S. Ang } \\ \text { EC } & \text { Mr. J. Riesgo } & \text { SOUTH AFRICA } & \text { Dr. T. Mali } \\ \text { FINLAND } & \text { Mr. M. Korkiakoski } & \text { SWEDEN } & \text { Dr. J. Sjödin } \\ \text { FRANCE } & \text { Mr. C. Coulaud } & \text { SWITZERLAND } & \text { Mr. A. Eckmanns } \\ \text { GERMANY } & \text { Dr. R. Drese } & \text { UNITED STATES } & \text { Dr. B. Habibzadeh }\end{array}$

CHAIRMAN

Mr. Werner Weiss

AEE - Institute for Sustainable Technologies

Feldgasse 19

A-8200 Gleisdorf

AUSTRIA

Tel: $+43 / 31 / 2588617$

e-mail:w.weiss@aee.at
SHC SECREIIARIAT

Ms. Pamela Murphy

KMGroup

913। S. Lake Shore Dr.

Cedar, MI 49621

USA

Tel: + I/231/620-0634

e-mail: secretariat@iea-shc.ors 